\title{
Optimal placement of facts devices to reduce power system losses using evolutionary algorithm
}

\author{
Mahmood Khalid Zarkani ${ }^{1}$, Ahmed Sahib Tukkee ${ }^{2}$, Mohammed Jasim Alali ${ }^{3}$ \\ ${ }^{1,2}$ Department of Construction and Projects, University of Kerbala, Karbala, Iraq \\ ${ }^{3}$ Department of electrical and electronic engineering, University of Kerbala, Karbala, Iraq
}

\begin{tabular}{l} 
Article Info \\
\hline Article history: \\
Received Sep 24, 2020 \\
Revised Nov 26, 2020 \\
Accepted Dec 10, 2020 \\
\hline Keywords: \\
Differential evolution \\
FACTS devices \\
Objective function \\
Optimal location and size \\
Power flow
\end{tabular}

Article Info

Article history:

Received Sep 24, 2020

Revised Nov 26, 2020

Accepted Dec 10, 2020

Power flow

\begin{abstract}
The rapid and enormous growths of the power electronics industries have made the flexible ac transmission system (FACTS) devices efficient and viable for utility application to increase power system operation controllability as well as flexibility. This research work presents the application of an evolutionary algorithm namely differential evolution (DE) approach to optimize the location and size of three main types of FACTS devices in order to minimize the power system losses as well as improving the network voltage profile. The utilized system has been reactively loaded beginning from the base to $150 \%$ and the system performance is analyzed with and without FACTS devices in order to confirm its importance within the power system. Thyristor controlled series capacitor (TCSC), unified power flow controller (UPFC) and static var compensator (SVC) are used in this research work to monitor the active and reactive power of the carried out system. The adopted algorithm has been examined on IEEE 30-bus test system. The obtained research findings are given with appropriate discussion and considered as quite encouraging that will be valuable in electrical grid restructuring.
\end{abstract}

This is an open access article under the CC BY-SA license.

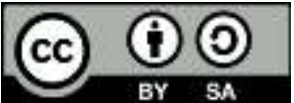

\section{Corresponding Author:}

Mahmood Khalid Zarkani

Department of Construction and Projects

University of Kerbala. 56001, Karbala, Iraq

Email: mhm_mhm_80@yahoo.com

\section{INTRODUCTION}

Electricity production and distribution companies are undergoing a major transformation in the concept of electrical energy supply around the world. The change in the public market, the expansion of cities and the increasing demand for electricity in addition to the turmoil in the prices of natural resources are among the most important motives that make the companies looking for new technologies contribute to the best service to the consumers.

One of the technologies that have been used recently is the FACTS devices as an effective way to the further enhances in the capabilities of transmitting electrical energy without need to construction a new costly transmission lines [1-5]. The efficiency of current power transmission systems can be increased and made to operate with better reliability through the use of FASTS devices with flexible power flow. The flow of electrical power through an alternating current transmission line depends mainly on the line resistance, the size of the wires and the phase angle difference between the sending and receiving end of the transmission line [6]. Although adding FACTS devices with electric power transmission networks leads to additional flexibility of power flow, it leads to an increase in technological problems and adds new economic costs [7]. In recent years, many scientific studies and research have emerged discussing possible solutions to find the best use of the FACTS devises. 
Choosing the best location in the electric power transmission network and modeling the possible solutions for installing FACTS devices has been discussed in [8]. In power systems suffering from congestion due to overloads, the site of FACTS devices are determined based on factors considered to be more sensitive and according to the nature of the load by solving the transmission problem In [9]. In [10], artificial intelligence methods of genetic algorithm were used to find the best place to install four types of FACTS devices-TCSC, UPFC, thyristor controlled voltage regulator (TCVR) and SVC. Various problems of improving the electrical power transmission systems are addressed by reducing system losses, improving line voltages, as well as increasing power transmission capacity using the particle swarm optimization (PSO) application is addressed in [11]. In [12] the main objective of the research was the economic cost of integrating the FACTS devices with the power transmission systems.

Annealing simulation to control the economic cost of power flow has been studied in [13]. Where the performance of the power transmission system was coupled without the use of FACTS devices and after adding several types of them, where the active power is controlled using a decoder to find the best location. The main objective behind this study is to reduce the losses and improve the voltage profile of the electrical power distribution system by finding the optimal location and sizing for three types of FACTS devices using one of the artificial intelligence (AI) techniques called (DE). In the Section 2, a brief overview of the FACTS devices techniques and types is presented. In the Section 3, the basic principles of the DE optimizing method is reviewed. In the Section 4, the methodology that used in this study is presented. In the Section 5, the results are collected. Finally, the results in the Section 6 are analyzed and discussed.

\section{FACTS DEVICES}

The use of FACTS devices has become common in modern electric power transmission and distribution systems to improve the stability and reliability of networks, in addition to increasing the fixed limits of transmission lines, which are often either thermal or insulated limits [14]. Basically, there are three main types of FACTS devices depending on the way of connection with the power transmission networks, which are series controllers, shunt controllers, combined series-shunt controller as shown in Figure 1 [15]. The serial controllers are injection of the series voltage at the connection point to deal with cases of the disturbance voltages Figure 1(a). In the shunt controllers, the electrical current is injected to the network through the contact point Figure 1(b) while the electric current is injected into the network by the shunt portion of the controllers and the series voltage is injected by the serial portion in the combined controller Figure 1(c) [16].

According to these classifications, there are many FACTS devices that are similar in their principle of work and differ in their design technique. In this study, three main types were used [17]:

a) TCSC (Thyristor controlled series capacitor). This type of device is used to increase line limits to transmit electrical power and to control the line overloads.

b) SVC (Static var compensator). This type of FACTS device is often used to compensate the low voltage of the line by injecting a reactive power directly or indirectly into the line contact bus.

c) UPFC (Unified power flow controller). This type is used to control and increase the power flow of the system and support system voltage profile.

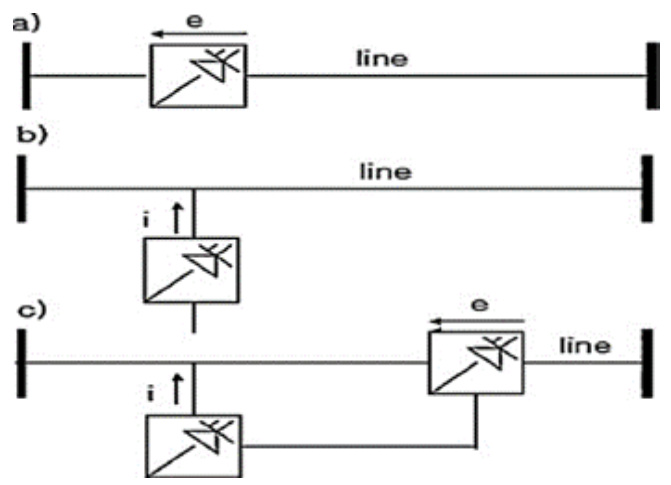

Figure 1. The basic patterns of FACTS devices, (a) series controller (b) shunt controller (c) combined seriesshunt controller 


\section{DIFFERENTIAL EVOLUTION TECHNIQUE}

Differential evolution technique (DE) is one of the evolutionary computation methods which has been utilized in many fields of engineering sciences. DE depends on stochastic real parameter optimization algorithms [18]. Practically, DE was applied in the operations of optimization by R. Storn and K. V. Price in 1995 to solve nonlinear, non-differentiable and multimodal objective functions. Furthermore, DE is characterized by its need for a less stochastic approach and uses rather a greedy selection than other classical evolution algorithms (EAs) to solve optimization problems. DE works through a simple cycle of stages that are presented in Figure 2 [19].

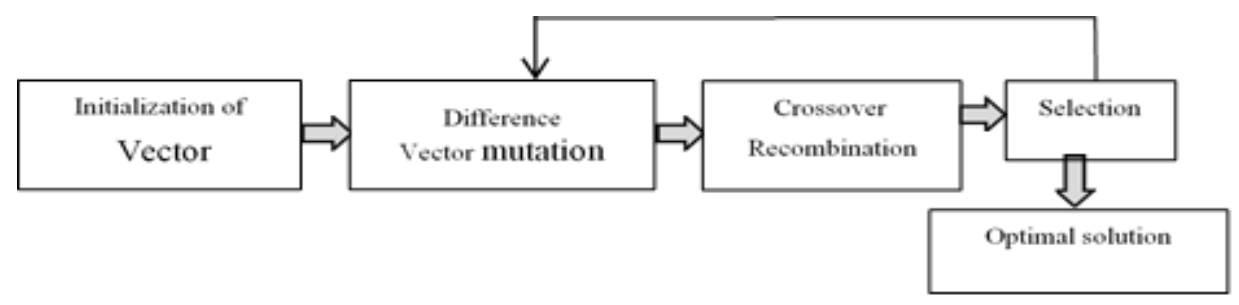

Figure 2. Cycle stages of the DE optimization method

DE method is a parallel direct search algorithm that uses size of the population (NP) and floating point for each individual solution as candidate solutions as in (1).

$$
P^{(G)}=\left[X_{1}^{(G)}, \ldots, X_{i}^{(G)}, \ldots X_{N P}^{(G)}\right]
$$

During the optimization process, the DE method maintains the population $\mathrm{P}^{(\mathrm{G})}$ for each generation (NP) vector for each candidate solution $\left(\mathrm{X}_{\mathrm{i}}\right)$ of the problem. The vector $\left(\mathrm{X}_{\mathrm{i}}\right)$ is an integer-value of $\mathrm{D}$ dimensional vector that depends on decision parameters (D) of the problem as given in (2).

$$
X_{i}^{(G)}=\left[X_{1 . i}^{(G)}, \ldots, X_{j, i}^{(G)}, \ldots, X_{D . i}^{(G)}\right], i=1, \ldots, N_{p}, j=1, \ldots, D
$$

In recent years, DE methods have been widely used as a powerful tool in the field of optimization where it has many advantages like, straightforwardness and simplicity in application, speed in performance, contains fewer parameters and low complexity of search space. All these features have made the DE method one of the best and most popular methods [20].

\section{THE PROPOSED APPROACH}

To achieve the main objective of this study that is reduced system losses after adding the FACTS devices in suitable locations within a power system, the system considerations must be given at acceptable and desirable limits of voltage, active and reactive power of the entire power system [21]. These limits are considered as inequality constraints of the work as shown below:

$$
\begin{aligned}
& P_{n i}^{\min } \leq P_{n i} \leq P_{n i}^{\max } \\
& Q_{n i}^{\min } \leq Q_{n i} \leq Q_{n i}^{\max }
\end{aligned}
$$

Where: $P_{n i}, Q_{n i}$ and $V_{i}$ assigned to active, reactive generated power and bus voltage magnitude respectively. $P_{n i}^{\min }, P_{n i}^{\max }$ are min and max active power generated. $Q_{n i}^{\min }, Q_{n i}^{\max }$ are min and max reactive power generated. $V_{i}^{\min }, V_{i}^{\max }$ are min and max voltage limits at bus $(i)$. When UPFC devices are integrated with the system, the series voltages are injected into the contact point at a maximum limit of $(0.1) \mathrm{V}$ max. Vmax is the maximum transmission line voltage, while the operating range belong to the angle is from $-180^{\circ}$ to $+180^{\circ}$. TCSCs act as the load inductive or capacitive compensator by controlling the line reactance. The maximum capacitance magnitude is ranged at ( -0.8 to 0.2$) \mathrm{X}_{\mathrm{L}}$, and $\mathrm{X}_{\mathrm{L}}$ is considered as the line reactance [22].

SVC can be worked within the system as either inductive or capacitive compensation. Consequently, it can be designed with two parallel perfect switched elements; capacitive and inductive [23]. The steps that have been adopted after the observance of the limits mentioned above in this research are as following: 
Step 1: Calculate the active and reactive power of the test system in the base case, and determine the total power losses and voltage profiles.

Step 2: Determine the test system lines that have the highest active and reactive power as a candidate location to install the different types of FACTS devices.

Step 3: Apply the DE optimizing method for all candidate buses to detect the best size of FACTS devices and calculate the test system losses.

Step 4: Repeat the above steps after increasing the total load of the system by $100 \%, 125 \%$ and $150 \%$ from base case.

\section{RESULTS AND DISCUSSION}

\subsection{The optimal location}

In this study, the candidate locations for installing the FACTS devices are initially determined by evaluating the active and reactive power flowing in each line within the adopted IEEE 30 bus test system. The overall system load is increased to $150 \%$ from the base case in the same proportion for all buses. The overload is met by the generator connected to the slack bus. Table 1 illustrates the active and reactive power flow pattern excluding the FACTS devices. The work results were obtained using newton raphson method [24].

Table 1. Active and reactive power of the test system without FACTS devices

\begin{tabular}{|c|c|c|c|c|c|c|c|c|c|}
\hline \multirow{2}{*}{ Line no. } & \multirow{2}{*}{ Bus-bus } & \multicolumn{2}{|c|}{ Base Case } & \multicolumn{2}{|c|}{ Loading $100 \%$} & \multicolumn{2}{|c|}{ Loading $125 \%$} & \multicolumn{2}{|c|}{ Loading $150 \%$} \\
\hline & & $\mathrm{P}$ & Q & $\mathrm{P}$ & Q & $\mathrm{P}$ & Q & $\mathrm{P}$ & Q \\
\hline 1 & $1-2$ & 0.902 & 0.013 & 0.905 & 0.014 & 0.907 & 0.015 & 0.908 & 0.017 \\
\hline 2 & $1-3$ & 0.477 & -0.003 & 0.479 & -0.002 & 0.480 & -0.002 & 0.484 & -0.019 \\
\hline 3 & $2-4$ & 0.288 & -0.058 & 0.290 & -0.051 & 0.291 & -0.047 & 0.292 & -0.043 \\
\hline 4 & $3-6$ & 0.446 & -0.027 & 0.446 & -0.025 & 0.448 & -0.024 & 0.451 & -0.021 \\
\hline 5 & $2-5$ & 0.158 & 0.029 & 0.160 & 0.031 & 0.163 & 0.035 & 0.165 & 0.039 \\
\hline 6 & $2-6$ & 0.378 & -0.051 & 0.380 & -0.049 & 0.381 & -0.047 & 0.383 & -0.046 \\
\hline 7 & $4-6$ & 0.392 & 0.024 & 0.394 & 0.026 & 0.395 & 0.028 & 0.396 & 0.030 \\
\hline 8 & $5-7$ & -0.130 & 0.029 & -0.128 & 0.031 & -0.126 & 0.034 & -0.123 & 0.037 \\
\hline 9 & $6-7$ & 0.363 & 0.033 & 0.365 & 0.035 & 0.367 & 0.037 & 0.369 & 0.039 \\
\hline 10 & $6-8$ & -0.027 & 0.013 & -0.024 & 0.015 & -0.023 & 0.017 & -0.021 & 0.021 \\
\hline 11 & $6-9$ & 0.151 & -0.110 & 0.154 & -0.108 & 0.156 & -0.105 & 0.159 & -0.102 \\
\hline 12 & $6-10$ & 0.114 & -0.031 & 0.117 & -0.028 & 0.119 & -0.024 & 0.123 & -0.019 \\
\hline 13 & $9-11$ & -0.179 & -0.225 & -0.175 & -0.222 & -0.172 & -0.219 & -0.169 & -0.216 \\
\hline 14 & $9-10$ & 0.325 & 0.031 & 0.329 & 0.034 & 0.332 & 0.041 & 0.337 & 0.044 \\
\hline 15 & 4-12 & 0.268 & -0.068 & 0.271 & -0.065 & 0.274 & -0.061 & 0.276 & -0.057 \\
\hline 16 & $12-13$ & -0.169 & -0.301 & -0.166 & -0.298 & -0.164 & -0.295 & -0.160 & -0.293 \\
\hline 17 & $12-14$ & 0.076 & 0.019 & 0.079 & 0.023 & 0.082 & 0.027 & 0.085 & 0.030 \\
\hline 18 & $12-15$ & 0.175 & 0.041 & 0.178 & 0.045 & 0.179 & 0.048 & 0.183 & 0.051 \\
\hline 19 & $12-16$ & 0.067 & 0.016 & 0.070 & 0.019 & 0.073 & 0.023 & 0.076 & 0.027 \\
\hline 20 & $14-15$ & 0.014 & 0.002 & 0.018 & 0.007 & 0.022 & 0.009 & 0.026 & 0.012 \\
\hline 21 & $16-17$ & 0.031 & -0.042 & 0.034 & -0.038 & 0.037 & -0.035 & 0.040 & -0.032 \\
\hline 22 & $15-18$ & 0.056 & 0.009 & 0.059 & 0.011 & 0.063 & 0.015 & 0.067 & 0.019 \\
\hline 23 & $18-19$ & 0.024 & -0.010 & 0.027 & -0.080 & 0.031 & -0.004 & 0.036 & -0.001 \\
\hline 24 & $19-20$ & -0.070 & -0.034 & -0.068 & -0.031 & -0.065 & -0.028 & -0.061 & -0.023 \\
\hline 25 & $10-20$ & 0.093 & 0.044 & 0.097 & 0.047 & 0.103 & 0.049 & 0.107 & 0.053 \\
\hline 26 & $10-17$ & 0.058 & 0.037 & 0.061 & 0.039 & 0.067 & 0.043 & 0.064 & 0.046 \\
\hline 27 & $10-21$ & 0.160 & 0.033 & 0.164 & 0.037 & 0.168 & 0.039 & 0.172 & 0.043 \\
\hline 28 & $10-22$ & 0.078 & 0.021 & 0.082 & 0.024 & 0.085 & 0.029 & 0.089 & 0.034 \\
\hline 29 & $21-22$ & 0.015 & -0.020 & 0.018 & -0.017 & 0.022 & -0.014 & 0.026 & -0.011 \\
\hline 30 & $15-23$ & 0.048 & 0.014 & 0.052 & 0.018 & 0.057 & 0.021 & 0.059 & 0.026 \\
\hline 31 & $22-24$ & 0.062 & 0.020 & 0.065 & 0.025 & 0.068 & 0.027 & 0.071 & 0.030 \\
\hline 32 & $23-24$ & 0.016 & -0.001 & 0.019 & -0.000 & 0.023 & 0.004 & 0.027 & 0.007 \\
\hline 33 & $24-25$ & -0.009 & -0.007 & -0.005 & -0.005 & -0.003 & -0.001 & -0.001 & 0.001 \\
\hline 34 & $25-26$ & 0.035 & 0.022 & 0.039 & 0.027 & 0.043 & 0.029 & 0.047 & 0.033 \\
\hline 35 & $25-27$ & -0.044 & -0.031 & -0.040 & -0.028 & -0.037 & -0.024 & -0.032 & -0.025 \\
\hline 36 & $28-27$ & 0.163 & -0.038 & 0.167 & -0.034 & 0.172 & -0.029 & 0.175 & -0.024 \\
\hline 37 & $27-29$ & 0.061 & 0.015 & 0.067 & 0.012 & 0.073 & 0.009 & 0.075 & 0.005 \\
\hline 38 & $27-30$ & 0.070 & 0.016 & 0.073 & 0.020 & 0.077 & 0.023 & 0.080 & 0.025 \\
\hline 39 & $29-30$ & 0.037 & 0.006 & 0.040 & 0.009 & 0.042 & 0.012 & 0.045 & 0.019 \\
\hline 40 & $8-28$ & 0.042 & 0.008 & 0.047 & 0.011 & 0.049 & 0.017 & 0.053 & 0.023 \\
\hline 41 & $6-28$ & 0.135 & 0.052 & 0.139 & 0.057 & 0.142 & 0.060 & 0.145 & 0.064 \\
\hline
\end{tabular}


As is evident, the active power which is flowing in the lines 6, 7 and 4 is considered as very high, where these lines are connected between the buses $(2,6),(4,6)$ and $(3,6)$ respectively. Thus, these lines are identified as a candidate location to install UPFC devices. The lines 41, 25 and 18 have also been found to carry large reactive power flow, so they are identified as a candidate sites for installing TCSC devices since these are the top three reactive energy carriers. Finally, lines 27, 26 and 9 were found to have the highest, second and third highest reactive power flow in the test system respectively. Hence, the buses 17, 7 and 21 which represent the end of the lines above are considered as the selective buses to install SVC devices where injection of reactive power in these buses can led to improve the system performance. Table 2 shows the candidate lines and buses for installing various types of FACTS devices.

Table 2. Location of different FACTS devices in the30 bus test system

\begin{tabular}{cccc}
\hline \multirow{2}{*}{ Type of FACTS } & \multicolumn{3}{c}{ Candidate position } \\
& $1^{\text {st }}$ position & $2^{\text {nd }}$ position & $3^{\text {ed }}$ position \\
\hline TCSC & Line 41 (6-28) & Line 25 (10-20) & Line 18 $(12-15)$ \\
UPFC & Line 6 (2-6) & Line 7 (4-6) & Line 4 (3-4) \\
SVC & Bus 17 & Bus 7 & Bus 21 \\
\hline
\end{tabular}

\subsection{The optimum size}

The DE optimization method is applied to determine the optimum value of the various FACTS devices after they are installed on the candidate sites and then calculate the total power losses of the IEEE 30 Bus test system. IEEE 30-bus system consists of 6 generating units and 41 transmission lines. The total real power losses of base case when the system operates without FACTS devices is $17.5280 \mathrm{MW}$ and the reactive power losses is attained at 68.8881MVar [25]. The DE technique is accomplished with several parameters that assigned in Table 3.

Table 4 shows the active and reactive power losses of the test system with UPFC devices in the candidate buses. It is clear that; line 4 (between buses 3-4) is the optimum location for UPFS devise with optimal sizing 9.854 MW. The total power losses of the system became 15.755, 16.198 and $16.743 \mathrm{MW}$ with $\%$ decreasing, while, reactive power losses become 61.227, 62.516 and 62.854 MVar when the test system is loaded $100 \%, 125 \%$ and $150 \%$ respectively. In Table 5, the results of the candidate lines power losses with TCSC devises are tabulated. Line 41 (between buses 6-28) is considered as the optimal location of TCSC with 9,640 MW size. The total real power losses becomes 15.531, 15.764 and 15.934 MW and the reactive power losses are 63.560, 63.865 and 64.706 MVar with increasing of the system load respectively. From Table 6, bus 21 is selected as the optimal location to install SVC device with optimum size is 9,720 MW. The overall active and reactive power losses of test system are 14.897, 15.674 and 15.864 MW and 62.015, 63.278 and 64.214 MVar respectively with different loaded.

Table 3. Parameters of the DE method

\begin{tabular}{cc}
\hline \multicolumn{2}{c}{ Differential evolution parameters } \\
\hline Variable Size D*5 & 15 \\
Maximum Generation $(\mathrm{Gen} \max )$ & 100 \\
Crossover Probability $(\Omega \mathrm{c})$ & 0.9 \\
Mutation probability $(\Omega \mathrm{m})$ & 0.2 \\
Initial size range & $0-10$ \\
\hline
\end{tabular}

Table 4. Total power losses of 30 bus system with UPFC device with different loading

\begin{tabular}{cccccccc}
\hline \multirow{2}{*}{ UPFC Location } & UPFC Size & \multicolumn{2}{c}{ Total losses Loading 100\% } & \multicolumn{2}{c}{ Total losses Loading 125\% } & \multicolumn{3}{c}{ Total losses Loading 150\% } \\
& MW & MW & MVar & MW & MVar & MW & MVar \\
\hline Line 6 (2-6) & 9.8624 & 15.817 & 61.457 & 16.201 & 62.544 & 16.761 & 62.874 \\
Line 7 (4-6) & 9.7851 & 15.921 & 61.389 & 16.311 & 62.672 & 16.788 & 62.911 \\
Line 4 (3-4) & 9.8546 & 15.755 & 61.227 & 16.198 & 62.516 & 16.743 & 62.854 \\
\hline
\end{tabular}

Table 5. Total power losses of 30 bus system with TCSC device with different loading

\begin{tabular}{cccccccc}
\hline \multirow{2}{*}{ TCSC Location } & TCSC Size & \multicolumn{2}{c}{ Total losses Loading 100\% } & \multicolumn{2}{c}{ Total losses Loading 125\% } & \multicolumn{2}{c}{ Total losses Loading 150\% } \\
& MW & MW & MVar & MW & MVar & MW & MVar \\
\hline Line 41 (6-28) & 9.640 & 15.531 & 63.560 & 15.764 & 63.865 & 15.934 & 64.706 \\
Line 25 (10-20) & 9.476 & 15.592 & 63.578 & 15.772 & 63.893 & 16.247 & 64.844 \\
Line 18 (12-15) & 9.600 & 15.603 & 63.564 & 15.816 & 64.101 & 16.312 & 64.937 \\
\hline
\end{tabular}


Table 6. Total power losses of 30 bus system with SVC device with deferent loading

\begin{tabular}{cccccccc}
\hline \multirow{2}{*}{ SVC Location } & SVC Size & \multicolumn{2}{c}{ Total losses Loading 100\% } & \multicolumn{2}{c}{ Total losses Loading 125\% } & \multicolumn{2}{c}{ Total losses Loading 150\% } \\
& MW & MW & MVar & MW & MVar & MW & MVar \\
\hline Bus 17 & 9.632 & 15.756 & 62.456 & 15.954 & 63.475 & 16.018 & 63.871 \\
Bus 7 & 9.648 & 15.369 & 62.315 & 15.841 & 63.435 & 15.971 & 63.977 \\
Bus 21 & 9.720 & 14.897 & 62.015 & 15.674 & 63.278 & 15.864 & 64.214 \\
\hline
\end{tabular}

The voltage profile of the whole test system has improved significantly after adding different types of FACTS devices as shown in Figure 3. It is clear; SVC achieves the greatest improvement in the level of voltages with deferent buses.

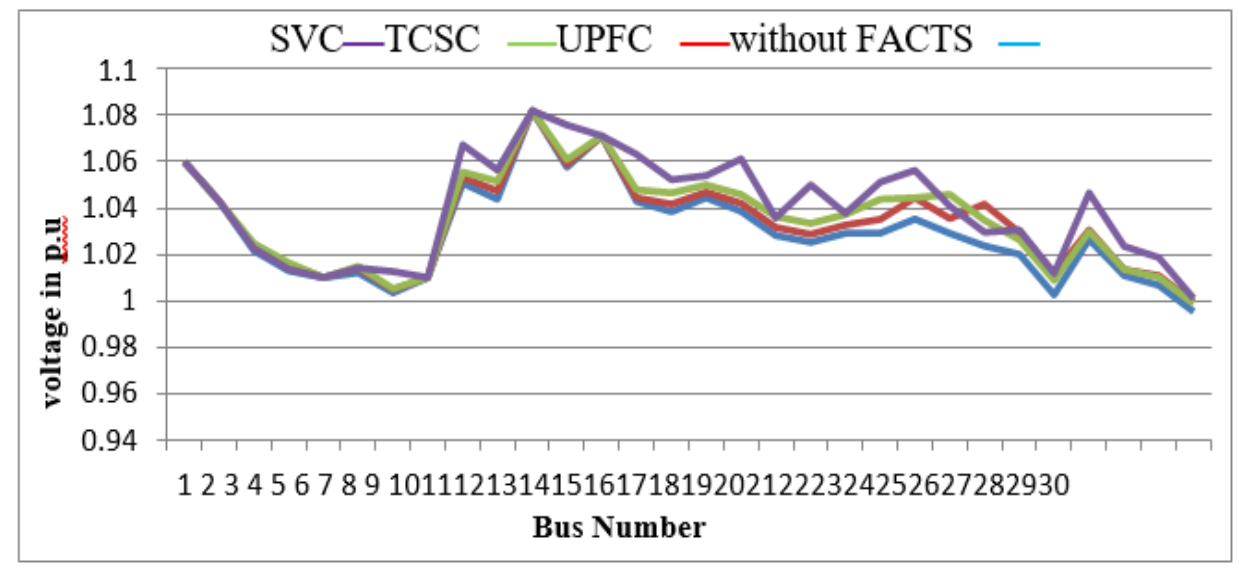

Figure 3. Comparison of voltage profiles with different FACTS devices

\section{CONCLUSION}

Recent studies have proven the importance of using FACTS devices within power networks to improve the performance and efficiency of electric power transmission networks. In this research, the addition of UPFC at the optimal location has led to a decrease in the system losses by percentage of $0.015 \%$, $0.010 \%$ and $0.005 \%$ with different loading criteria. When installing the TCSC device in the line 44, the system losses are decreased by $0.017 \%, 0.015 \%$ and $0.013 \%$, while the bus 21 is the best place to install the SVC device in the test system, with reduced losses of $0.023 \%, 0.015 \%$ and $0.014 \%$.

\section{ACKNOWLEDGEMENTS}

Researchers like to thank the presidency of University of Kerbala/Karbala/Iraq for providing continuous support for the researchers, also do not forget give thanks and gratitude to the Deanship of the Faculty of Engineering to bring them necessary to complete this research facility.

\section{REFERENCES}

[1] Akpeke, N. E., Muriithi, C. M., \& Mwaniki, C, "Contribution of FACTS devices to the transient stability improvement of a power system integrated with a PMSG-based wind turbine," Engineering, Technology \& Applied Science Research, vol. 9, no. 6, pp. 4893-4900, 2019.

[2] Yao, Wei, et al., "Wide-area damping controller of FACTS devices for inter-area oscillations considering communication time delays," IEEE Transactions on Power Systems, vol. 29, no. 1, pp. 318-329, 2014. doi: 10.1109/TPWRS.2013.2280216.

[3] Singh, Naveen, and Piyush Agnihotri, "Power system stability improvement using FACTS devices," Int J Advance Research and Development, vol. 3, no. 4, pp. 171-176, 2018.

[4] Selvakumaran, S., and S. M. Kalidasan, "Power quality improvement in transmission systems using facts devices." 2016 Online International Conference on Green Engineering and Technologies (IC-GET). IEEE, pp. 1-4, 2016.

[5] Patil, Basanagouda, and S. B. Karajgi, "A review on optimal placement of FACTS devices in deregulated environment-a detailed perspective," 2017 International Conference on Electrical, Electronics, Communication, Computer, and Optimization Techniques (ICEECCOT). IEEE, pp. 375-380, 2017. doi: 10.1109/ICEECCOT.2017.8284532. 
[6] Lal, D. K., \& Barisal, A. K., "Comparative performances evaluation of FACTS devices on AGC with diverse sources of energy generation and SMES," Cogent Engineering, vol. 4, no. 1, 2017.

[7] D. J. Gotham and G. T. Heydt, "Power Flow Control and Power Flow Studies for system with FACTS Devices," IEEE Trans on Power System, vol. 13, no 1, 1998.

[8] Gerbex, S., Cherkaoui, R., \& Germond, A. J., "Optimal location of multi-type FACTS devices in a power system by means of genetic algorithms," IEEE transactions on power systems, vol. 16, no. 3, pp. 537-544, 2001.

[9] Singh, S. N., \& David, A. K., "Optimal location of FACTS devices for congestion management," Electric Power Systems Research, vol. 58, no. 2, pp. 71-79, 2001.

[10] Radu, D., \& Besanger, Y., "A multi-objective genetic algorithm approach to optimal allocation of multi-type FACTS devices for power systems security,” In 2006 IEEE Power Engineering Society General Meeting, IEEE, pp. 1-8, June 2006.

[11] Gaur, D., \& Mathew, L., "Optimal placement of FACTS devices using optimization techniques: A review," In 3rd International Conference on communication Systems, IOP Conference Series, Material Science and Engineering, pp. 1-15, March 2018. doi:10.1088/1757-899X/331/1/012023.

[12] Bhattacharyya, B., \& Kumar, S., "Loadability enhancement with FACTS devices using gravitational search algorithm," International Journal of Electrical Power \& Energy Systems, vol. 78, pp. 470-479, 2016.

[13] Aghaebrahimi, M. R., Golkhandan, R. K., \& Ahmadnia, S., "Localization and sizing of FACTS devices for optimal power flow in a system consisting wind power using HBMO," In 2016 18th Mediterranean Electrotechnical Conference (MELECON), pp. 1-7, April 2016.

[14] Singh, N., \& Agnihotri, P., "Power system stability improvement using FACTS devices," Int J Advance Research and Development, vol. 3, no. 4, pp. 171-176, 2018.

[15] Malatji, E. M., Twala, B., \& Mbuli, N., "Optimal placement model of multi- type FACTS devices in power system networks on a limited budget," In 2017 IEEE AFRICON, pp. 1296-1300, 2017. doi: 10.1109/AFRCON.2017.8095669.

[16] Malatji, E. M., Twala, B., \& Mbuli, N., "Comparison of Different Optimal Placement Models of FACTS Devices in Power System Networks on a Limited Budget," In 2019 7th International Conference on Smart Grid (icSmartGrid), pp. 108-112, 2019. doi: 10.1109/icSmartGrid48354.2019.8990740.

[17] Chirantan, S., Swain, S. C., Panda, P. C., \& Jena, R., "Enhancement of power profiles by various FACTS devices in power system," In 2017 2nd International Conference on Communication and Electronics Systems (ICCES), pp. 896-901, 2017.

[18] Caraffini, F., \& Kononova, A. V., "Structural bias in differential evolution: A preliminary study," In Proceedings leGo-14 $4^{\text {th }}$ International Global Optimization Workshop, AIP Conference Proceedings, 2019. https://doi.org/10.1063/1.5089972.

[19] Wahab, Noor Izzri Abdul, Ahmed Sahib Hammadi, and Mohammad Lutfi Othman, "Optimal Location and Size of Distributed Generation to Reduce Power Losses based on Differential Evolution Technique," Pertanika J. Sci. \& Technol 25, 169-178, 2017.

[20] Hadi, Mahmood Khalid, Mohammad Lutfi Othman, and Noor Izzri Abd Wahab, "Special protection and control scheme for transmission line overloading elimination based on hybrid differential evolution/electromagnetism-like algorithm," J Electrical Engg Tech. vol. 12, no. 5, pp. 1729-1742, 2017. DOI: 10.5370/JEET.2017.12.5.1729.

[21] Elmitwally, A., \& Eladl, A., "Planning of multi-type FACTS devices in restructured power systems with wind generation," International Journal of Electrical Power \& Energy Systems, vol. 77, pp. 33-42, 2016.

[22] Xiao, Ying, Y. H. Song, and Y. Z. Sun. "Power flow control approach to power systems with embedded FACTS devices," IEEE Transactions on power systems, vol. 17, no. 4, pp. 943-950, 2002. DOI: 10.1109/TPWRS.2002.804919.

[23] L. Kumar, S. Kumar, S. Kumar Gupta and B. K. Raw, "Optimal Location of FACTS Devices for Loadability Enhancement using Gravitational Search Algorithm," 2019 IEEE 5th International Conference for Convergence in Technology (I2CT), pp. 1-5, 2019. doi: 10.1109/I2CT45611.2019.9033561.

[24] H. Le Nguyen, "Newton-Raphson method in complex form [power system load flow analysis]," in IEEE Transactions on Power Systems, vol. 12, no. 3, pp. 1355-1359, Aug. 1997. doi: 10.1109/59.630481.

[25] C. Barrows et al., "The IEEE Reliability Test System: A Proposed 2019 Update," in IEEE Transactions on Power Systems, vol. 35, no. 1, pp. 119-127, Jan. 2020. doi: 10.1109/TPWRS.2019.2925557.

\section{BIOGRAPHIES OF AUTHORS}

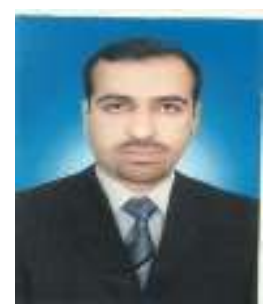

Mahmood Khalid Zarkani, received the B.Sc. degree in Electrical and Electronic Engineering from University of Babylon, Babylon, Iraq, in 2005. The M.Sc. degree in Electrical Power Engineering from Universiti Putra Malaysia (UPM), Malaysia, in 2016. Currently, he is a lecturer and researcher at the Department of Electrical and Electronic Engineering, Faculty of Engineering, University of Kerbala, Iraq. He also practices as an electrical engineer in electrical services installation works. His areas of research interest include, Power Engineering, Control Engineering, simulation, and design of power systems. 


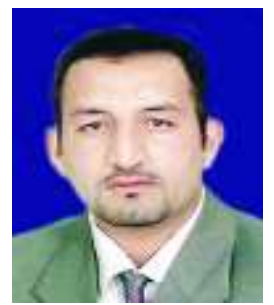

Ahmed Sahib Tukkee was born in Karbala, Iraq, in 1974. He received the B.Cs. degree in electrical engineering from the University of Technology, Bagdad, Iraq, in 1997, and the master degree in electrical engineering from the University Putra Malaysia (UPM) Malaysia, in 2016. In 2017, he joined the Department of Electrical Engineering, University of Kerbala, Iraq as a Lecturer. His research interest includes, Power Engineering, Control Engineering, and power system.

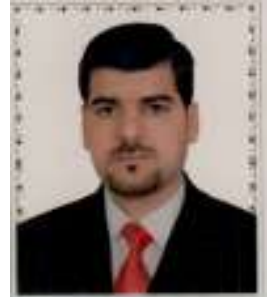

Mohammed Jasim Alali was born in Karbala, Iraq, in 1984. He received the B.Sc degree in information and communications engineering from the University of Baghdad, Bagdad, Iraq, in 2007, and the Master degree in electronics communication engineering from the University of Nottingham, UK, in 2016. In 2017, he joined the Department of Electrical and electronic Engineering, University of Kerbala, as a Lecturer. His research interest includes, Communication Engineering, Information Engineering, designing of low noise amplifiers. 